CJD from psychiatric sources might allow the earlier referral of a minority of cases, but the evidence suggests that the psychiatric community are promptly referring cases of new variant CJD for a neurological opinion.

\section{Future occurrence and diagnosis}

New variant CJD is a rare disease, but there is a possibility that large numbers of cases could occur in future years. Psychiatrists should be aware of the psychiatric symptoms of this disease and of the diagnostic difficulties in the early stage. The diagnosis of new variant CJD is often not possible until the occurrence of frank neurological symptoms and signs, but the suspicion of this diagnosis may be raised in the early stages if there is evidence of cognitive impairment or persistent limb pain, paraesthesia or dysaesthesia in association with the psychiatric symptomatology. Other early neurological features in some cases include gait imbalance, dysarthria, blurring or double vision, involuntary movements, dysgeusia and dysgraphia.

Although there has been an extended latency in onward referral for a neurological opinion in a small number of cases, this probably reflects an extended, initially non-specific, psychiatric phase and overall there is only a short latency between psychiatric and neurological referral. Limited data suggests that there may be neuropsychological evidence of cognitive impairment prior to the development of neurological symp- toms. Early diagnosis is important to relatives of patients and the developments of early diagnostic markers is an important objective.

\section{References}

BRUCE, M. E., WILL, R. G., IRONSIDE, J. W., et al (1997) Transmissions to mice indicate that 'new variant' $\mathrm{CJD}$ is caused by the BSE agent. Nature, 389, 498-501.

WILL, R. G., IRONSIDE, J. W., ZEIDLER, M., et al (1996) A new variant of Creutzfeldt-Jakob disease in the UK. Lancet. 347, 921-925.

ZEIDLER, M. STEWART, G. E., BARRACLOUGH, C. R. et al (1997a) New variant Creutzfeldt-Jakob disease: neurological features and diagnostic tests. Lancet, 350, 903-907.

-. JohnStone. E. C., BAMBER, R. W. K., et al (1997b) New variant Creutzfeldt-Jakob disease: psychiatric features. Lancet, 350, 908-910.

*R. G. Will, Professor of Clinical Neurology, University of Edinburgh and Director of National CJD Surveillance Unit, Western General Hospital, Edinburgh EH4 2XU; G. Stewart, Research Registrar, National CJD Surveillance Unit; M. Zeidler, Research Registrar, National CJD Surveillance Unit; M. A. Macleod Research Registrar, National CJD Surveillance Unit and R. S. G. Knight, Consultant Neurologist, National CJD Surveillance Unit and Western General Hospital, Edinburgh

*Correspondence

\title{
Survey of suicides in the Fife region of Scotland
}

\author{
Fergus Douds and Vicky Bridges
}

\begin{abstract}
Aims and methods Suicides in the Fife region were investigated over a two-year period. The timing of the final contact with general practitioners and psychiatric services was ascertained. Data were collected from procurators fiscal records, general practices, and where applicable, psychiatric records.

Results There were 74 suicide victims during the study period. Forty-six per cent of suicide victims saw their general practitioner in the month before death, and $55 \%$ had a history of previous contact with psychiatric
\end{abstract}

services, although only $27 \%$ of this group saw a psychiatrist in the month before death.

Clinical implications Clinical audit of suicide is an important task for psychiatric senvices. Practitioners must continually assess risk and attempt, where possible, to reduce risk factors.

The Fife region, situated north of Edinburgh, has a mixed urban/rural population of 350000 
people. Unemployment in the region is $1 \%$ higher than the Scottish average (7.4 v. 6.4\%, August 1997 figures; Office for National Statistics, 1997).

The purpose of the study was to complete a survey of all suicides in the Fife region during the period January 1995-December 1996, and subsequently to establish a clinical audit system of suicide within the Fife Psychiatric Service. Such an audit has been recommended by the Health of the Nation White Paper (Secretary of State for Health, 1992). We particularly wished to investigate the role of doctors in the prevention of suicides, looking at the final consultation with general practitioners and psychiatrists. Several similar studies have previously been published (Barraclough et al, 1974; Vassilas \& Morgan, 1993; Matthews et al, 1994).

\section{The study}

In Scotland the local procurators fiscal (Scottish equivalent of a coroner) are notified of all suicides by the police. A thorough investigation takes place, including interviews with relatives/ witnesses, which often provide a valuable 'snap shot' of the mental state and social circumstances prior to death. Toxicology and postmortem examination are routine. If the procurator fiscal and Crown Office (Edinburgh) are satisfied with the outcome of the investigation. there is no public inquiry.

Contact was first made with the three procurator fiscal officers in the region. Basic demographic data were collected for the purpose of this study, as well as cause of death, related events, toxicology results, and whether or not a suicide note was left by the deceased. Recent major life events were noted, though the lack of any comparison group to judge this reporting with is a limitation in the methodology.

Contact was next made with the deceased's general practitioner. If the deceased resided outwith the region a questionnaire was sent to his or her general practitioner, otherwise notes were accessed at the Health Board headquarters. The following data were obtained: date of, and nature of, last consultation; employment status; and details of prescribed medication.

Finally, it was ascertained whether the deceased had psychiatric records (i.e. past/present contact with the service). Notes were accessed and the following data obtained: date of last consultation; diagnosis; and grade of doctor. The general practitioners of those residing outwith the region were also asked to provide these data if available/applicable.

\section{Findings}

There were 74 suicide victims over the two-year period: 62 males and 12 females (ratio of approximately 5:1). In Scotland, over the same period of time, the ratio of male/female suicides was 3:1.
In the Fife region in the 10-year period prior to the study (1985-1994) there were 404 reported suicides, 277 males and 127 females (a ratio approximately $2: 1$ ). This anomaly, in the gender ratio of victims, seems likely to be accounted for by the small size and timescale of this study. Twenty-six of the victims were aged under 35 years, 24 of them were male; eight were aged over 65 (one female); 19 of the deceased were single. 25 married/cohabiting, 23 divorced/separated and seven widowed; $28 \%$ were employed and $45 \%$ unemployed; five of the deceased were not Fife residents.

\section{Contact with general practitioner services}

Three of the deceased were not registered with a general practitioner. In the week preceding the act, $20 \%$ of people had been seen by a general practitioner. In the previous 28 days, $46 \%$ of people had made contact with a general practitioner. The timing of final contacts with general practitioners is shown in Table 1 . The nature of the final consultation was looked at and in approximately $40 \%$ of cases was deemed by us to have been discernibly psychiatric.

\section{Contact with psychiatric services}

Forty of the suicide victims had a confirmed history of psychiatric contact. In the week preceding the act five had been seen by a psychiatrist, and in the previous 28 days 11 had been seen by a psychiatrist. The timing of final contact with psychiatric services is shown in Table 1. More than half saw a consultant at the final consultation; two were registered on the Care Programme Approach (both had schizophrenia) and 17 (out of 40) were active cases.

Psychiatric diagnosis was obtained from the narrative of the psychiatric notes inspected, although this was not subjected to review by a

Table 1. Timing of final contact with medical personnel

\begin{tabular}{lc}
\hline iming & $\mathbf{n = 7 4}$ \\
\hline General practitioner & \\
$>20$ weeks & 22 \\
$8-20$ weeks & 8 \\
$4-8$ weeks & 7 \\
1-4 weeks & 19 \\
< l week & 15 \\
Not registered & 3 \\
Psychiatrist & \\
$>20$ weeks & 19 \\
8-20 weeks & 3 \\
$4-8$ weeks & 4 \\
1-4 weeks & 6 \\
< l week & 5 \\
Don't know & 3 \\
\hline
\end{tabular}


Table 2. Psychiatric diagnosis

\begin{tabular}{lc}
\hline Diagnosis & $n=40$ \\
\hline Depression & 16 \\
Alcohol/drug misuse & 13 \\
Schizophrenia/schizo-affective & 3 \\
Bipolar illness & 1 \\
No mental illness & 4 \\
Other & 3 \\
\hline
\end{tabular}

diagnostic classification system. The range of diagnoses is listed in Table 2.

\section{Mode of death}

Hanging (22 cases), overdose (19) and carbon monoxide poisoning (13), were the most common causes of death. It is worth noting that in 15 of the 19 deaths from overdoses the substance taken was a prescribed psychotropic medication: seven of these deaths were the result of tricyclic drug (dothiepin or doxepin) overdose.

Twenty-seven of the deceased left suicide notes. Six of the deceased had a documented family history of suicide (first-degree relative). Over $40 \%$ of the victims had a documented history of deliberate self-harm.

\section{Life events}

For the majority of the deceased major life events were identifiable. Some had more than one life event. Relationship difficulties were most prevalent (26 cases), followed by illness (11), bereavement (seven) and financial difficulties (six).

\section{Comment}

This survey, albeit small in size, does replicate findings from other studies. In Barraclough et al's seminal paper from 1974, two-thirds of suicide victims were seen by a general practitioner in the month prior to death. Our finding of only $46 \%$, however, is in keeping with more recent studies (e.g. Matthews et al, 1994), as is the finding that in only $40 \%$ of cases the nature of the final consultation with general practitioners was discernibly psychiatric. Diekstra \& van Egmond (1989) found that only $48 \%$ of their cohort of suicides were seen by a general practitioner during the eight weeks prior to death. Although more than half of the suicide victims (40 out of 80 ) had previously seen a psychiatrist, only just over $25 \%$ of this group ( 11 of the deceased) had done so in the 28 days prior to death.

Reduction of mortality by suicide was identified by the Department of Health in England and Wales (Secretary of State for Health, 1992) as a health objective to be considered when assessing the effectiveness of Mental Health Services. The fact that only 11 out of 74 suicide victims in the study saw a psychiatrist in the $\mathbf{2 8}$ days prior to death, illustrates the inherent difficulties of such an objective.

These are perhaps pessimistic findings with respect to suicide prevention. Overcoming fatalistic attitudes to prevention is important. Morgan et al (1996) suggested that an increase in clinical confidence could be achieved by presenting the basic facts about suicide, challenging negative attitudes and discussing the relevant clinical techniques. Murphy (1984) stated that the prevention of suicide, of course, generated no data, meaning that 'successes' could never be proven, but surely could not be doubted. Many deaths may be unavoidable, but practitioners must still concentrate on reducing risk (e.g. almost $10 \%$ of deaths in this study were attributable to tricyclic drug overdoses) and looking for 'avoidable' cases. The formation of case registers is invaluable for the clinical audit of suicide and such audit important for on-going education, refreshing clinical skills and to prevent attitudes of hopelessness and complacency in staff groups.

\section{Acknowledgements}

We thank the procurator fiscal offices for their cooperation and Mrs Doris Brown for her help in preparing the manuscript.

\section{References}

Barraclough, B., Bunch, J., Nelson, B., et al (1974) A hundred cases of suicide: clinical aspects. British Journal of Psychiatry, 125. 355-373.

Diekstra, R. F. W. \& VAN Egmond, M. (1989) Suicide and attempted suicide in general practice 1979-86. Acta Psychiatrica Scandinavica, 79, 268-275.

MATTHEWS, K. MILNE, S. \& ASHCROFT, G. W. (1994) Role of doctors in the prevention of suicide: the final consultation. British Journal of General Practice, 44 345-348.

Morgan, H. G., Evans, M., Johnson, C., et al (1996) Can a lecture influence attitudes to suicide prevention. Joumal of the Royal Society of Medicine, 89, 87-90.

MURPHY, G. E. (1984) The prediction of suicide risk: Why is it so difficult? American Journal of Psychotherapy. $\mathbf{8 8}$ 341-349.

OFFICE FOR NATIONAL STATISTICS (1997) Labour Market Trends. London: The Stationery Office.

SECRETARY OF STATE FOR HEALTH (1992) The Health of the Nation: A Strategy for Health in England. London: HMSO.

VAssilas, C. A. \& MORGaN, H. G. (1993) General practitioners' contact with victims of suicide. British Medical Journal. 307, 300-301.

*Fergus Douds, Specialist Registrar in Learning Disabilities/General Psychiatry, Edinburgh Healthcare NHS Trust, William Fraser Centre, Tipperlinn Road, Morningside, Edinburgh EH10 5HF; and Vicky Bridges, Specialist Registrar in Old Age Psychiatry, St Lawrence Hospital. Bodmin

*Correspondence 